\title{
Intelligent, Innovative and Sustainable Industry in Bulgaria - Prospects and Challenges
}

\author{
Assoc. Prof. D-r Eng. \\ Desislava Petrova \\ Department Management \\ Faculty of Economics \\ Technical University of Gabrovo \\ Gabrovo, Bulgaria \\ des_petrova@abv.bg
}

\begin{abstract}
The report analyzes industrial transformation through smart and sustainable growth, as well as building a culture of innovation in a new digital age. Innovative enterprises from Bulgaria are presented with their respective modern organizational structures and forms of innovative cooperation between them - Sofia Techpark, Trakia Economic Zone, Technological Park at the Technical University of Gabrovo. The barriers to innovation development of SMEs in Bulgaria are outlined. An example of a high technology center funded under the EU Operational Programs is presented. Answers to questions such as: what are the role of the innovation centers in the innovation ecosystem in Bulgaria; how to stimulate the transfer of talent between university and business; how the market for innovation of the future changes; why deliteracy is a factor of success; how to support innovation and digitization; what are the European policies in the field of innovation and digitization?
\end{abstract}

Keywords-innovation, new organizational structures, technological development, smart industry, transfer of innovation.

\section{INTRODUCTION}

The percentage of innovative enterprises in Bulgaria is low - only $16 \%$ of all enterprises in industry. This is all the more relevant for SMEs. This is also confirmed by the data included in the Innovation Scoreboard developed by the European Commission. Bulgaria lags significantly behind the EU average levels by a number of indicators $[6,8]$ :

- $\quad$ low R \& D expenditure - $0.5 \%$ of GDP;

- low share of innovative enterprises receiving public support for innovation - $0.8 \%$;

- low degree of commercialization of the Bulgarian research activity;

- low level of cooperation between business and research institutions and universities - 10\%;

- low share of innovative SMEs cooperating with other SMEs - 3.1\%;

- low share of SMEs performing organiza-tional innovations - $11 \%$;

- $\quad$ low exports of high-tech products $-3.3 \%$.

In Bulgaria relatively the most innovative are the sectors of "Computer Technologies", "Engineering and consultancy activities", "Financial intermedia-tion".

SMEs strive to achieve results through innovation activity by increasing the quality and diversification of the product mix. Gradually realize the role of competitive advantages of a higher rank and, above all, of their innovative solutions, related to the reduction of the cost of raw materials and energy efficiency [2].

In Bulgaria, the creation of new knowledge and the transfer of the existing one takes place in several directions:

- $\quad$ participation in international research pro-grams and partnerships between business, scientific circles and public administration;

- $\quad$ transfer of innovation through direct and foreign investment;

- international trade co-operation;

- $\quad$ transfer of knowledge and innovative prac-tices through local business contacts with foreign partners through contracts such as suppliers, subcontractors, distributors, etc.;

- exploiting the potential of the local inno-vation system.

The conclusions of the Lisbon European Council are aimed at: maximizing the benefits of innovation in research at national and EU level as well as creating a favorable environment for the emergence and development of an innovative business. EU innovation trends are: encouraging research that is turning into innovation; increasing the deployment of new technologies by enterprises; encouraging investment in innovation; creating technological "valleys"; increa-sing the importance of the service sector; directing innovation to environmental protection, etc.

The knowledge economy requires strong science and highly qualified specialists. The share of scientists in enterprises in the Republic of Bulgaria is the lowest among all surveyed countries [6]. 
Here is where we can look for answers to the following questions:

- what is the role of the innovation centers in the innovation ecosystem in Bulgaria;

- how can the transfer of talent between universities and business be stimulated;

- how the innovation market of the future will change;

- why de-literacy is a factor for success;

- how innovation and digitization are supported;

- what are the European policies in the field of innovation and digitization;

- where are the centers of science and technology in Bulgaria?

\section{EXPLANATION}

The modern organizational structures is built on the basis of the project organization with a dynamic organizational structure [1]. When we have large and complex projects with a long duration in time we create so-called clean design structures. With in them, all management functions are executed, from planning to controlling, the involved specialists are directly subordinated to the project manager, as well as the resources for the implementation of the project.

The design structure depends on the size of the project group. It should be noted that the matrix structures are characterized by the simultaneous use of functional and target elements. To perform certain tasks, target groups are created, involving specialists from the functional departments of the organization. Matrix organization is a flexible and dynamic structure. There is an opportunity for regrouping the resources by changing the environment and creating conditions for creative expression of the specialists. In the high-tech industries, the so-called "structures of the future". As such, the orchestrated structure, which has a limited practical application, can be mentioned. Its main elements are [1]:

- "orchestra" - a person in the organization who acts as a coordinator of the actions of the operational and innovation loop;

- $\quad$ executive groups - innovators work on them;

- sponsors (guarantors) - their task is to "push" innovation and order new ideas.

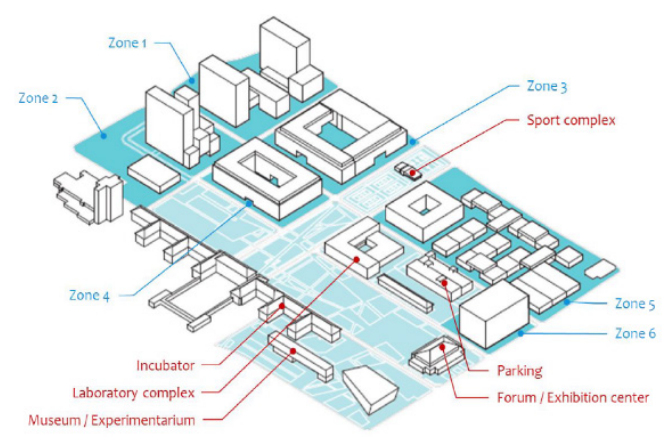

Fig. 1. Sofia Techpark
Examples of these types of new organizational structures are the Sofia Techpark (Fig. 1) and Trakia Economic Zone (Fig. 2).

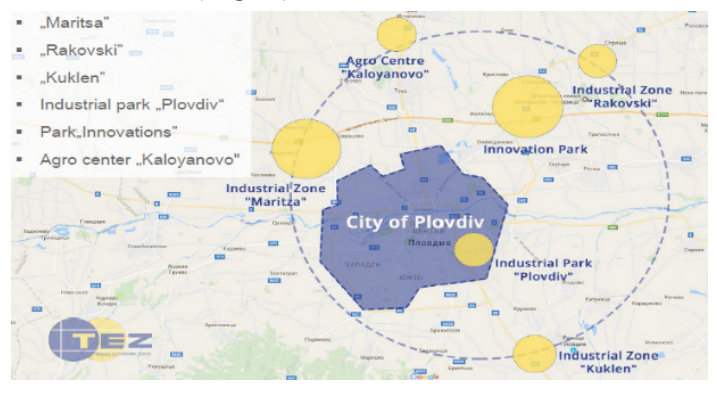

Fig. 2. Trakia Economic Zone (TEZ)

The information and communication infrastructure covers the storage and transmission environment of information and knowledge. At the macro level, it includes national and local fixed and wireless voice and data networks and user access devices. At the micro level, key features of the information and communication infrastructure are the availability of intercompany computer and communication networks, software applications and protocols. It should be noted that despite the rapid and homogeneous development by 2016 the information and communication infra-structure in the Republic of Bulgaria lags behind the average level of the new EU member states. The pro-duction activity carried out in Bulgarian SMEs does not require welldeveloped ICT. These enterprises are still peripheral equipment but not network commu-nication. The share of enterprises with IT systems for operational management of production is small. For most businesses in Bulgaria, the internet remains the only means of communication and much less used for online marketing or e-commerce. This trend in 2016 has rapidly changed in the direction of increase. In order to assess the ICT activity in the European Commission, they monitor the indicators: working in high-tech areas and exporting these products as part of total exports; selling new products for market and new products for companies; working in mediumhigh-tech and high-tech industries.

According to the Organization for Economic Cooperation and Development (OECD) classification, high-tech industries are those for the production of: drug substances and products; office and electronic computing; radio, television and telecommunication equipment; aircraft and spacecraft and their engines [3].

The index for the export of high-tech products measures the country's technological competitiveness, the ability to realize the results of the research and the realization of the international markets. It is important to note that by this indicator Bulgaria is equal to the average for the EU countries. Over the last 5 years, the share of R \& $\mathrm{D}$ spending in the mid-high-tech and high-tech sectors of industry amounted to approxi-mately $80 \%$ of the total cost of industrial research and innovation costs. The indicator for ICT investments as a percentage of total costs reflects the fundamental specificity of the knowledge-based 
economy, the driver of present and future productivity improve-ments. These investments include equipment, services and software. In order to enhance the role of ICT in the innovative economy in the country, the following measures should be taken to:

- development of ICT infrastructure with access to e-services by society;

- reengineering the network of the state administration;

- $\quad$ ensuring high information security by building an effective information environ-ment and interaction standards;

- $\quad$ setting up centers of excellence in the field of ICT;

- $\quad$ building and supporting technology plat-forms in the ICT field;

- $\quad$ promoting a public-private partnership for more investment and innovation in the ICT sector.

Innovative forms of cooperation implemented in Bulgaria - Business Incubators [4]. The incubator is a complex multifunctional complex that performs a variety of innovative services and can be located in one or several buildings and works on the principle of synergy (Figure 3 ).

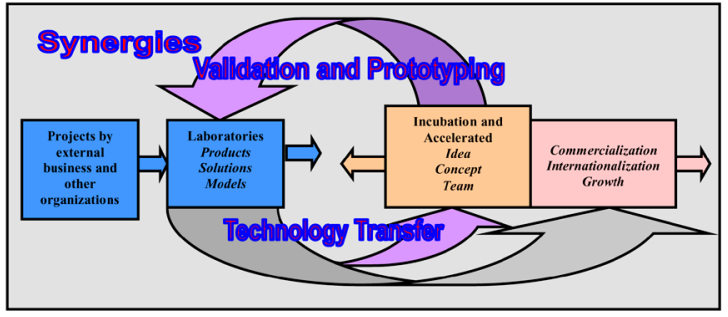

Fig. 3. Principal scheme of Incubator work by Sofia Techpark

There is an opportunity to significantly reduce the costs of a start-up entrepreneur as a result of the renting of a work space, the necessary equipment and a wide range of highly qualified consulting and information services on all aspects of entrepreneurial activity. Payment of the services provided, including the rent of the premises, the use of the equipment and servicing belonging to the incubator is at moderate prices as a result of the participation of the government, the local authorities, the large organizations and universities involved in the financing of the incubator's activity.

For 2018 Sofia Techpark has 24 high-tech compa-nies and 21 startups. For 2019, Co-working Spaces for up to 60 teams and starters, an author's incubation program, and a multitude of added-value services are foreseen. Emphasis is placed on turning science into products. Promotes and supports entrepreneurship in the field of research and development in Bulgaria and the Balkan region. It works directly with teams and consultants from the Silicon Valley. It has the longest incubation and acceleration program, with a period of up to 3 years. The criteria for inclusion in the structure of the business incubator can be defined as follows: a clear and realistic business idea with market potential, at least $30 \%$ of its personnel being engaged in research and development, active interaction with the labora-tory complex on the territory of Sofia
Techpark.

Other successful forms of development of the innovation activities of the organizations are the technology parks and technopolis.

Technological parks (Technoparks) are a major tool for stimulating technological innovation activity in existing enterprises, in start-ups or in research institutes. At the same time, the term "technology park" includes the terms "science park" or "research park" and "innovation center".

By definition, the technology park is a place where newly established technology companies can find an appropriate intellectual environment, as well as support for the start-up and development of their business, access to markets, technologies, and so on. The Technological Park is a scientific-production territorial complex with a complex hierarchical structure. As an example we can point to Sofia Techpark, schematically presented in Fig. 1.

The laboratory complex is one of the main elements of the technology park. At Sofia Techpark there are 11 certified laboratories (biopharmaceuticals, bioinformatics, high-performance computations, artifi-cial intelligence and CAD systems, cyber security, 3D creativity and fast prototyping of new products, virtual and expanded reality, intelligent communication structures, nano-technology, etc.) and works with 3 universities.

Technopolis is a complete science-production structure created on the basis of a separate city, in the economy of which technological parks and incubators have a significant place. The university or other higher education institution is the core of technopolis. The biggest technopolis in the world is the Silicon Valley, and Bulgaria is not yet there. There are built-up areas in the country, such as the Trakia Economic Zone (TEZ), represented in Figure 2. At present, the con-struction of a zone of this type between Gabrovo and Sevlievo is being considered, where the two centers of production of products of ABB, Podem - AD, Ideal Standard, Mechatronica, STS - holding group and others are considered.

\section{Barriers to the innovation development of SMEs in} Bulgaria

We can define the Bulgarian market as a relatively small one, characterized by low purchasing power and low consumer demand. Our country is among those countries where consumers are mistrustful of innova-tion and, as a whole, lack an innovation culture among the population [5]. The following main factors, which prevent the Bulgarian SMEs from successfully deve-loping their innovative activities, are identified and they relate to:

- $\quad$ the nature of the innovation process (high costs and high economic risk);

- lack of sources to finance innovation activities (mostly from own funds or from attracted investment capital);

- $\quad$ state of the business environment;

- lack of adequate infrastructure to develop innovation; 
- a disconnected link between science and business;

- $\quad$ shortage of qualified staff;

- lack of sufficient information on markets and new niche markets;

- $\quad$ shortcomings in the operation of key support mechanisms and instruments (e.g. National Innovation Fund).

The establishment of Centers for Innovation in the Innovation Ecosystem in Bulgaria has begun in order for the industrial transformation to improve the competitiveness of the Bulgarian industry. Creating them will lead to stimulation of the transfer of talent between university and business; to change the market for innovation; to degeneration; to the imple-menttation of European policies on innovation and digitization. Here, it is worth noting that the total budget foreseen under the procedure "Construction and Development of Centers of Competence" in the Republic of Bulgaria is worth BGN 150 million and is divided into the following components $[7,8,9]$ :

- $\quad$ Mechatronics and clean technologies - BGN 48 million;

- Informatics and Information and Communication Technologies - BGN 27 million;

- Industry for healthy life and biotechnology BGN 48 million;

- New technologies in the creative and recreational industries - BGN 27 million.

Funding is under Priority Axis 1 "Research and Technological Development" of the Operational Program "Science and Education for Smart Growth", co-financed by the European Regional Development Fund. Approved after an open competition procedure are seven Competence Centers amounting to BGN 134 million under the Operational Program. The Managing Authority of the Science and Education for Smart Growth OP approved the evaluation committee's report on the evaluation and the ranking of the project proposals under the procedure BG05M2OP001-1.002 "Building and Development of Competence Centers" [8].

One of these national centers is the Competence Center "Intelligent Mechatronics, Eco and Energy Saving Systems and Technologies" at the Technical University of Gabrovo and PROJECT BG05M2OP001-1.002-0019 for "Clean Technologies for Sustainable Environment Water, Waste, Energy for Circular Economy "(Clean \& Circle).

PROJECT BG05M2OP001-1.002-0023 Compe-tence Center "Intelligent mechatronics, eco- and energy-saving systems and technologies" [9]

An opening press conference was given the start of a major project by which the Technical University Gabrovo is a leading organization, namely the Center for Competence Center "Intelligent Mechatro-nics, Eco and Energy Saving Technologies and Technologies", financed under the Operational Program "Science and Education for Smart Growth" 2014 - 2020, co-funded by the European Union, through the European Regional Development Fund. The grant is BGN 23569 719,17, of which BGN 20034 261,29 European funding and BGN 3 535457,88 nationally $[6,7,8,9]$.

The main objective is to build a sustainably functioning National Competence Center, in which the three sides of the knowledge triangle - education, research and business are in an effective and dynamic interaction based on shared strategies, strong and concrete engagements and joint scientific projects and partnership.

The project partners are seven: Technical University of Gabrovo, Technical University of Sofia, Technical University of Varna, Sofia University "St. Kliment Ohridski”, Institute of Robotics - BAS, Institute of Electronics - BAS, Central Laboratory of Applied Physics - Bulgarian Academy of Sciences.

Associated partners are - authoritative industrial enterprises and business associations, as well as technical universities in Berlin and Liberec. The implementation period is until the end of November 2023.

According to University Rector and Project Leader Prof. Raycho Ilarionov, "The idea is to create a technology center, a competence center or a technology park variant at the Technical University of Gabrovo. The university is working on four more projects and has three more competence centers and a center of excellence. The idea is to unite all these projects in one place and to create a Technology Park at the Technical University of Gabrovo to create highly intelligent and technological devices, to train young engineers and $\mathrm{PhD}$ students and to create science for the benefit of business (Fig. 4)." The efforts of seven leading scientific organizations and universities in Bulgaria to increase the level of their scientific research and the successful commerciali-zation of the results obtained in a priority for the economy "Mechatronica and pure technologies" as defined in the Innovation Strategy for smart specialization 2014 - 2020 (ISSS).

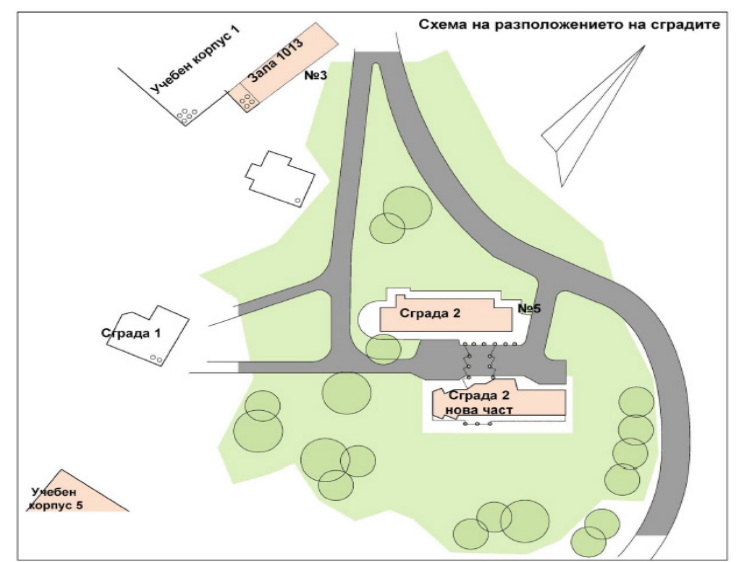

Fig. 4. Technological Park at the Technical University of Gabrovo [9]

The Center of Competence has two major pillars - scientific laboratories and scientific projects to be worked on. One part is intelligent mechatronic systems, and the second part is energy-saving systems and clean technologies. There are two other pillars for disseminating results and for training and qualification - introducing 
new training and education methods, marketing and dissemination of results. The aim is to bring research results, to get faster to real business, to translate into practice. Thus, people in education and science and business people will be even more useful to each other, and the transfer of innovation and science to the economy will be real.

The activities are numerous. The first major task is to modernize existing research infrastructures. These are two very big renovations at the Technical University Sofia branch in Plovdiv and at the Technical University in Gabrovo, as well as at the partners of the Institute of Robotics and Sofia University "St. Kliment Ohridski". A total of BGN 4859206.00 is foreseen for repair activities. The second important activity is the purchase of equipment necessary for the realization of the research programs for over BGN 13.5 million. The third core activity concerns the real work of scientists - conducting market-oriented research and development, moderni-zing new technologies at a high international level. For this purpose, about BGN 4 millions are planned under the project. Funds are also provided for the accredita-tion of laboratories so that businesses can not go to make measurements abroad but use the services of the Competence Center. It is clear from the envisaged activities that the project is in fact infrastructure - infrastructure for conducting research and its disse-mination and its implementation as innovation in business.

One of the expected results of its implementation is to provide capacity for research and innovation teams in the field of mechatronics and clean techno-logy by attracting leading research organizations. The other expected result is the retention and attraction in the Republic of Bulgaria of young researchers, scientists and doctoral students by creating modern conditions for research and development. The third result is the practical application of the research results achieved. Fourthly, the results with practical applica-tion or representing the experimental development of technology and technology will be made available to the Technology Transfer Committee to coordinate intellectual property rights protection activities and their subsequent commercialization.

The project itself is an opportunity for inclusion in other international programs and projects. With its implementation, Gabrovo Center for Competence with 33 laboratories in 8 laboratory complexes, 14 joint projects between the Center and the business, research and innovation, etc. will be established. Laboratory 1013 is equipped with the latest generation and works as a development engineer at the Faculty of Mecha-nical and Instrumentation at the University.

The Center's research program reflects the horizontal strands of the Innovation Strategy for Smart Specialization, namely the development of the inno-vative potential in the field of Mechatronics and Clean Technologies for the creation and adaptation of new technologies leading to improved resource efficiency, competitive advantages and increased added value of the products in the production of specialized equip-ment, machine building and instrumentation, compo-nents for production of automobiles, servo systems, electric electrical and electromechanical products, robotics, chemical products.

The acquisition of new knowledge and skills for teaching and the transformation of this knowledge into innovations of interest to the Bulgarian and European economies are a leading factor in all strategies, plans, programs and their corresponding implementing measures.

The joint $\mathrm{R} \& \mathrm{D}$ of the Center and the business should lead to increased private investment in public R \& D and complementing public spending with public-private partnerships and projects implemented in cooperation with the business sector. This will allow the Competence Center to develop and become a place where science, business, government, and education get their hands on. The established scientific infra-structure, in line with the best world standards and practices, will promote the development of applied science and innovation in the field of mechatronics and clean technologies to create economic growth, quality jobs and help address national, European and global challenges for society.

Here we have to emphasize that the comercialization of research results is a guarantee of a fully realized potential of the Center for Competence Research Plan. Knowledge transfer is bi-directional - the "active supply" model refers to the commercial application of the knowledge acquired by the research system through intellectual property, technology transfer, and "spinoff" companies, and the "active search" model is where companies receive support from researchers because they have signed cooperative / partnership contracts.

The joint R \& D of the Center and the business should lead to increased private investment in public R \& D and complementing public spending with public-private partnerships and projects implemented in cooperation with the business sector.

This will allow the Competence Center to be the place where science, business, government, and education go hand in hand. The developed scientific infrastructure, in accordance with the best world standards and practices, will promote the development of applied science and innovation in the field of mechatronics and clean technologies in Bulgaria and will provide the opportunity for a more competitive Bulgarian economy.

We are currently working on a Concept for the use of the funds from the "Intelligent Growth Science and Education" Operational Program for the Operational Program "Innovation and Competitiveness" to support the Regional Innovation Centers (RICs). The main objective here is to build and develop a modern research and innovation infrastructure and expertise for conducting applied open-ended research and development activities, facilitating the accelerated economic and social development of the Bulgarian regions. The research infrastructure is part of the scientific and innovation system in Bulgaria in the priority areas of the Innovation Strategy for Intelligent Specialization (ISIS). The 
procedure for development and implementation under Operational program on innovation and competitiveness (OPIC) Priority Axis 1 "Technological Development and Innovation". The main focus is to explore and further develop the research and development potential of research organizations as part of the RIC in cooperation with regional business to create new products, services and processes. They will find investment in open and shared science and innovation infrastructures. Work will be done on enhancing cooperation, networking and knowledge transfer, as well as achieving higher levels of technological readiness. All these efforts are focused on the horizon 2021-2027.

\section{CONCLUSION}

In conclusion, the following conclusions can be drawn:

- $\quad$ the essence of innovative enterprises is re-vealed with their respective modern organi-zational structures;

- schemes of business incubators, technology parks and technopolis (Sofia Techpark, Trakia Economic Zone, Technological Park at the Technical University of Gabrovo);

- forms of innovation cooperation defined;

- the barriers to the innovation development of SMEs in Bulgaria have been formulated, highlighting the main factors behind the development of their innovation activities;

- an example is the Center for Competence "Intelligent Mechatronics, Eco-Energy and Energy Saving Systems and Technologies" at the Technical University of Gabrovo and PROJECT BG05M2OP001-1.002-0019 for "Clean Technologies for Sustainable Environment Water, Waste, Energy for a Circular Economy" ( Clean \& Circle);

- the role of the innovation centers in the innovation ecosystem in Bulgaria is defined;

- the way of stimulating the transfer of talent between university and business is defined;

- the link between innovation, de-literacy, smart industry and the future is formulated.

The realization of projects under the procedure "Building and Development of Competence Centers" in the Republic of Bulgaria will lead to the improvement of the competitiveness of the Bulgarian economy, shortening and eliminating the distance "scienti-fic achievements" - "real technologies" - "business".

All this proves the author's thesis on the road to intelligent, innovative and sustainable industry in Bulgaria. Current issues, prospects for industry-specific research, as well as alternative solutions against rapid innovation technology aging are proven.

\section{REFERENCES}

[1] A. Vasileva, Modern forms of international business, Sofia, 2010.

[2] D. Damyanov, Innovation Policy, Ed. "Interview Press", Sofia, 2002, ISBN 954-666-029.

[3] N. Nikolova, Entrepreneurial Development of the Gabrovo Industry - Economic Indicators and Structure. VI International Scientific and Applied Conference on Contemporary Issues in the Theory and Practice of Business Management, Varna, 26.0602.07.2006.

[4] D. Petrova, Europe 2020 and Transfer on Innovation in Bulgaria, „Research and Development in Mechanical Industry“ RaDMI 2012, 13-17 September 2012, Vrnjačka Banja, Serbia, SaTCIP Ltd., Technical-Mechanical School in Trstenik, ISBN 978-866075-036-7, Volume I, pp. 261-265.

[5] D. Petrova, S. Dimitrova, Europe 2020 - The New Strategy for Smart, Sustainable and Inclusive Growth and Bulgarian Industrial Competitiveness, Rezekne 2011, Latvia, Rezekne Higher Education Institution, Faculty of engineering, Proceeding of the $8^{\text {th }}$ International Scientific and Practical Conference June 20-22, 2011, Volume I, ISSN 1691-5402, pp. 333-339.

[6] http://eurofunds.bg/

[7] www.gabrovo.bg

[8] www.minfin.government.bg

[9] www.tugab.bg 